\title{
IDENTIDADES EM (DIS)CURSO: PRÁTICAS DE MULTILETRAMENTOS DIDÁTICOS COM FUTUROS PROFESSORES
}

\author{
Ana Patricia Sá Martins* \\ Dorotea Frank Kersch ${ }^{* *}$
}

\begin{abstract}
RESUMO: $O$ estudo em questão surgiu da necessidade de refletirmos acerca das práticas e identidades profissionais que se (re)(des)velam nas e por meio das variadas formas de lecionar Língua Portuguesa na atual conjuntura das tecnologias digitais. Foi proposta, portanto, uma abordagem discursiva a respeito das tecnologias digitais e sua repercussão na construção das identidades docentes na formação inicial. Nesse sentido, objetivamos discutir uma experiência pedagógica de pesquisaação desenvolvida com alunos do curso de Letras licenciatura noturno de uma universidade pública estadual na cidade de Balsas - MA. Desse modo, o trabalho visa a investigar como futuros professores de Língua Portuguesa representam, discursivamente, a (re) construção de suas identidades em função do papel das tecnologias digitais nas suas ações profissionais futuras. Com base nos pressupostos teóricos dos estudos culturais sobre Identidade, do Interacionismo Sociodiscursivo e dos (Multi)letramentos, as análises das vozes enunciativas nos projetos didático-digitais desenvolvidos pelos futuros professores revelaram a consciência destes no trabalho com os gêneros de texto e artefatos digitais, transformando-os em instrumentos de ensino, segundo as reais práticas sociais letradas dos contextos de letramento situado. Além disso, os discursos para o agir docente demonstraram reposicionamentos identitários docentes, ainda que em construção e num continnum, com traços de seus letramentos didático-digitais.
\end{abstract}

PALAVRAS-CHAVE: Identidades docentes; Formação inicial; Tecnologias digitais; Curso de Letras.

\section{Introdução}

"Como nos tornamos professores? Como decidir o que ensinar? Será que nós, professores, sabemos, afinal, por que e para que ensinar e aprender o que estamos ensinando?” Apesar de atuarmos na docência há décadas, tais questionamentos não surgiram em nossas reflexões durante a formação inicial ou no ingresso da carreira docente. Anos de estudos

\footnotetext{
* Doutora em Linguística Aplicada pela UNISINOS-RS. Professora do Departamento de Letras da Universidade Estadual do Maranhão (Uema), dedicando-se, principalmente, a pesquisas quanto a formação de professores e metodologias de ensino de Língua Portuguesa e Literatura no curso de Letras, sobretudo, nos seguintes temas: Tecnologias e mídias digitais, Gêneros digitais e ensino, Formação de professores, Multiculturalismo e Identidade docente.

** Doutora em Filologia Românica. Professora do Programa de Pós-Graduação em Linguística Aplicada da Unisinos. Realizou Estágio de pós-doutoramento na Texas Tech University, no College of Education.
} 
em cursos de formação continuada, especializações, mestrados e doutorados foram ressignificando nossa identidade docente e construindo sentidos às práticas de ensino que desenvolvemos.

Considerando essa reflexão inicial, passamos a refletir como nossas ações formativas nos cursos de licenciatura em Letras estão oportunizando aos nossos alunos e futuros professores possibilidades de experenciar práticas pedagógicas que os impulsionem à construção de suas identidades docentes fortes.

Observamos que várias são as pesquisas desenvolvidas com o intuito de compreender a ação dos alunos de licenciatura e futuros professores, durante o seu processo de formação (BUENO, 2007; MACHADO, 2004; CRISTOVÃO, 2006). Contudo, a maioria expressiva desses estudos refere-se ao contexto do estágio supervisionado, quando os futuros professores, pela obrigatoriedade curricular, desenvolvem seu trabalho no contexto escolar. Em virtude dessa constatação, questionamo-nos: Como é possível construir a identidade profissional de professor em momentos anteriores ao estágio supervisionado, vivenciando a docência na prática? Que práticas e discursos sobre ser professor contribuem para significar a profissão, convocando os sujeitos em formação a construírem (re)posicionamentos identitários na sua escrita sobre o agir docente?

Machado (2004) argumenta que a análise de textos produzidos sobre ou em situação de trabalho, compreendido como uma forma de agir em sociedade, pode conduzir à apreensão da natureza e das ações verbais que se configuram, bem como à compreensão sobre o papel que a linguagem desempenha em um determinado contexto. Nesse sentido, consideramos que a análise dos projetos didático-digitais voltados ao trabalho do futuro professor pode nos revelar como o seu agir foi construído no discurso para o agir.

Para tanto, desenvolvemos uma experiência pedagógica por meio de pesquisa-ação em uma universidade estadual do sul do Maranhão, com alunos do $4^{\circ}$ período noturno do curso de Letras licenciatura, durante a disciplina de Prática de Projetos Pedagógicos. Ao longo da disciplina, os licenciandos foram convidados a construírem projetos didático-digitais com gêneros textuais e tecnologias digitais como catalisadores, contando com a colaboração de seus alunos em escolas da rede municipal da cidade. Assim, ressaltamos a 
relevância da nossa investigação, haja vista examinarmos o trabalho dos futuros professores no $4^{\circ}$ período do curso de Letras, isto é, antes da primeira metade do curso. Acreditamos que isso possibilite maior espaço de intervenção formativa nas licenciaturas e nos dê subsídios para uma revisão curricular.

Desse modo, sistematizamos o presente trabalho, iniciando com a exposição dos pressupostos teóricos que embasam nossa investigação; em seguida, apresentamos os procedimentos metodológicos que orientaram a geração de dados e nossas análises. Posteriormente, discutimos e analisamos a escrita sobre e para o agir dos (futuros) professores nos projetos didático-digitais para, por fim, tecemos nossas considerações acerca da construção identitária docente a partir das práticas e discursos sobre ser professor que contribuem para (re)significar a profissão, convocando os sujeitos em formação a construírem (re)posicionamentos identitários na sua escrita sobre o agir docente.

\section{Identidade e formação docente}

Adentrar na discussão sobre as práticas formativas de futuros professores requer, a nosso ver, um olhar interdisciplinar, uma vez que é preciso considerar a complexidade multifatorial que caracteriza essas práticas. Não é só um ou outro aspecto; são vários que influem na construção identitária desse docente em formação. Alguns desses aspectos, inclusive, são individuais, subjetivos, mas eles carecem do olhar dialogizado dentro das condições históricas, sociais e culturais em que ocorrem. Nesse sentido, buscamos, no campo dos Estudos Culturais (EC), fundamentação para problematizar o tema da(s) identidade(s) docente(s), como também dialogamos com estudos da Sociologia, das Ciências da Educação e da Linguística Aplicada.

A contribuição dos Estudos Culturais nos ajuda a compreender o conceito de identidade no contexto da pós-modernidade, em que as identidades não são mais fixas, definitivas e previsíveis a partir de uma comunidade cultural específica que as determinam. Ao contrário, na modernidade, as identidades são provisórias, negociadas e renegociadas permanentemente. Isso sugere defini-las como identificações em curso, em constante processo 
de transformação. As identidades são, pois, compreendidas aqui como construções discursivas produzidas no interior das práticas sociais, culturais em que os sujeitos estão inseridos. Uma vez produzidas discursivamente, elas assumem características de mobilidade, dinamismo e indeterminação atribuídas à linguagem na visão pós-estruturalista (HALL, 2000, 2006; SILVA, 2011).

Nessa perspectiva, o sujeito é um ser sócio histórico construído a partir de suas relações com o mundo social, relações essas mediatizadas pela linguagem nas suas mais diferentes formas de manifestação. Logo, a linguagem verbal (discurso) representa material privilegiado de interação entre os indivíduos. Seu caráter dialógico anuncia o discurso como o lugar de onde emergem os sentidos que são produzidos pelos sujeitos numa inter-relação constitutiva. Nessa dinâmica discursiva, os sujeitos se constituem, constituem o outro e são constituídos por eles, sempre carregados de marcas históricas particulares e sociais de suas vidas em sociedade.

Em virtude de o nosso trabalho referir-se ao contexto da formação inicial de professores, considerando a possibilidade de constituição de processos de identificação docente, na perspectiva dos multiletramentos, consideramos também reflexões de estudiosos no campo da educação (OLIVEIRA, 2008; PIMENTA, 2012; NÓVOA, 1992), os quais apontam a natureza complexa da formação da identidade de professor, haja vista ela ser constituída a partir de fatores de ordem subjetiva e objetiva, os quais, articuladas, dão condições ao processo de construção identitária.

Autores como Nóvoa (1995) e Pimenta (2012) salientam a ideia de que a docência é um saber que se constrói na prática, no exercício da profissão. Para Pimenta (2012), o processo de construção da identidade profissional do professor tem um caráter histórico, sendo o sujeito situado em um tempo e um espaço, no qual cria conhecimento e o seu fazer profissional por meio de sua ação, tomadas as circunstâncias de uma determinada época da sociedade. Nesse sentido, compreendemos que a identidade do professor se dá fortemente na e pela experiência, ao contrário do que propunham os estudos essencialistas, que concebiam o professor como um ser vocacionado ou dotado de um dom herdado de gerações. 
Nessa perspectiva, como aponta a perspectiva dos Estudos Culturais, na interação, o sujeito age, transforma a si, ao outro e a realidade em fluxo permanente através da linguagem, não se configurando em mero produto do seu ambiente sócio histórico. Assim, as identidades tornam-se uma “celebração móvel” (HALL, 2006, p. 13) (trans)formadas continuamente, negociadas a partir das formas como somos interpelados pelas condições sociais em que estamos inseridos. Desse modo, identificar-se com uma profissão dependerá das representações construídas, aliadas aos sistemas/práticas culturais ao nosso redor, cujo processo de identificação é visto como algo nunca acabado.

Sob essa perspectiva, encontramos a pertinência de analisar os processos de identificação com a docência, através da (trans) formação dos futuros professores de língua materna, no interior de espaços formativos - no caso deste estudo, no curso de Letras, como também nas práticas sociais com/nas escolas da educação básica - espaços privilegiados (e de poder) de produção discursiva em torno dos vários aspectos de ordem política, social, pedagógica, que constituem os sentidos da profissão, marcando as suas identidades.

\section{O letramento situado dos (futuros) professores e seus desenvolvimentos profissio-} nais

Nossa proposta de trabalho parte da premissa de que letramento não é somente ler e escrever, mas exercer as práticas sociais de leitura e escrita com os gêneros que circulam na sociedade, conjugadas com as práticas sociais de interação oral e escrita. Situadas na perspectiva de Kleiman (1995, p. 11) acerca dos Estudos do Letramento, entendemos o termo letramento como "conjunto de práticas sociais, cujos modos específicos de funcionamento têm implicações para as formas pelas quais sujeitos envolvidos nessas práticas constroem relações de identidade e poder".

Desse modo, compreendemos que é necessário considerar o ensino com os gêneros, a partir de situações didáticas que oportunizem os mais diversos usos e funções da leitura e escrita, considerando, assim, as condições de produção da linguagem para diferentes interlocutores. Neste artigo, a formação inicial de professores é interpretada como lugar pri- 
vilegiado para práticas letradas e trabalho coletivo interativo, voltados à aprendizagem situada, num processo de (trans)formação para práticas didáticas multiletradas. Entretanto, depreendemos que adotar essa perspectiva de formação é, antes de tudo, conceber uma pedagogia por projetos, sustentada no desenvolvimento de competências no uso da leitura e da escrita relacionado à prática social.

Kenski (2011, p. 27) observa que "as tecnologias digitais introduzem uma nova dinâmica na compreensão das relações com o tempo e o espaço [...]", uma vez que estão ligadas à ideia de interatividade, interconexão, inter-relação entre as pessoas e os espaços virtuais de produção e disponibilização de informação. Notamos cotidianamente como nossas práticas sociais e nossas relações com/no mundo têm sofrido uma alteração significativa. Estudiosos como Martín-Barbero (2008), Gee (2001), Barton e Lee (2015) acreditam que isso se deve à influência da globalização num lugar antes tido como imutável, sólido e com um rizoma impossível de sofrer alterações.

As tecnologias digitais têm influenciado o modo de viver do ser humano, ainda que muitos não tenham se dado conta disso. A formação (inicial) docente também é influenciada por essas transformações. Cada vez mais, os papéis estáveis e determinados do professor e do aluno são questionados e ressignificados. Nessa conjuntura, novos letramentos e novas concepções identitárias do professor são reclamadas, principalmente para que esse seja um mediador no processo de construção do conhecimento.

Tendo em vista as novas exigências para um letramento crítico perante esse contexto multissemiótico, as universidades, no nosso caso, os cursos de formação inicial de professores de Letras, precisam refletir sobre novas práticas de construção de ensino e aprendizagem, tanto para os professores formadores quanto para os professores em formação. Práticas de formação inicial e continuada precisam dialogar com o uso didático das tecnologias, constituindo-se em um espaço integrado com as mídias, no qual professor e aluno interajam e construam sentido na produção do conhecimento. Desse modo, como alega Pimenta (2012), as transformações das práticas escolares só se efetivam na medida em que o professor amplia sua consciência sobre as próprias ações, sejam aquelas da sala de aula ou da escola como um todo. 
No que se refere ao trabalho do professor, variados são os estudos acerca do agir humano implicado nesse tipo de trabalho, que têm sido desenvolvidos no interior do quadro teórico-metodológico do Interacionismo Sociodiscursivo. Dentre os princípios de trabalho, estão o de que o agir humano se configura e reconfigura em textos e de que a textualidade guarda, em seus diferentes níveis, traços reveladores das ações de linguagem realizadas pelos sujeitos nas situações de trabalho (MATENCIO, 2010; MACHADO, 2004; 2005; CARNIN, 2015; MARTINS, 2020).

Nesse sentido, dá-se relevância às ações e discursos, constitutivas do trabalho do professor, materializadas em certos gêneros textuais, de modo que mereçam ser cada vez mais investigados, porque estudando condutas verbais particulares, percebemos as relações dialógicas sustentadoras dessas condutas. Compreender essas condutas nos interessa não somente porque somos professoras formadoras de professores, mas porque lidamos com necessidades de didatização, e, principalmente, porque acreditamos que analisar o trabalho do (futuro) professor implica compreender "como as ações de linguagem em que se engajam [os sujeitos] (re)dimensiona saberes e representações” (MATENCIO, 2010, p. 17).

No intuito de situarmos os construtos utilizados em nossa análise, apresentamos a proposta de arquitetura textual conforme concebida por Bronkart (1999; 2006). Para a análise da constituição do texto, Bronckart traz a metáfora do folhado textual (BRONCKART, 2006, p. 147) o qual ilustra a arquitetura textual que apresenta três camadas: a infraestrutura geral - nível mais profundo, os mecanismos de textualização nível intermediário, e os mecanismos enunciativos - nível superficial.

Para nossa investigação, é de especial interesse o conceito de mecanismos de responsabilização enunciativa, principalmente as vozes enunciativas (BRONCKART, 1999; 2006), que nos ajudam a verificar quem diz, vê e pensa o que nos textos dos futuros professores. Alicerçado na concepção dialógica da linguagem, Bronckart (1999, p. 326) explica que "as vozes podem ser definidas como entidades que assumem (ou às quais são atribuídas) a responsabilidade do que é enunciado". Ou seja, as vozes inscrevem as instâncias 
enunciativas, assumindo responsabilidade pelo que é dito (ou pensado). Na Figura 01, sistematizamos breves conceituações acerca do conceito nodal ao nosso trabalho: as vozes enunciativas.

Figura 1- Vozes enunciativas

\section{VOZES SOCIAIS:}

- Vozes de personagens grupos ou instituições sociais que não intervêm como agentes no percurso temático de um segmento textual, mas que são mencionadas como instâncias externas de avaliação de alguns aspectos desse conteúdo temático.

\section{VOZES DE PERSONAGENS}

- Vozes de seres humanos ou entidades humanizadas, implicadas na qualidade de agente. Segmentos de texto na $1^{\text {a }}$ pessoa gramatical: fusão do narrador/expositor e da voz que este põe em cena - o narrador assume, de algum modo, seu personagem. Segmentos de texto na $3^{a}$ pessoa gramatical: manutenção da distinção entre narrador/expositor e a voz secundária posta em cena.

\section{VOZ DO AUTOR}

- $\sqrt{ } \mathrm{OZ}$ que procede da pessoa que está na origem da produção textual e que intervém, como tal, para comentar ou avaliar alguns aspectos do que é enunciado.

Fonte: Martins (2020, p. 128).

Desse modo, partindo do construto teórico-metodológico do interacionismo sócio discursivo e das vozes enunciativas, pretendemos, neste trabalho, investigar como futuros professores de Língua Portuguesa representam, discursivamente, a (re) construção de suas identidades em relação ao papel das tecnologias digitais nas suas ações profissionais futuras. Para tanto, elegemos duas partes constitutivas do projeto didático-pedagógico construído pelos futuros professores, procurando evidenciar suas ações nessas fases de desenvolvimento: 1) justificativa, na qual as crenças profissionais são destacadas por meio de seu discurso; e 2) metodologia, através da qual encontramos as ações que esses futuros profissionais acreditam serem importantes para o desenvolvimento da aprendizagem de seus alunos, assim como identificamos os aspectos referentes aos modos do agir profissional, no que se refere ao estudo da língua materna, a partir das práticas sociais letradas dos estudantes. 


\section{Procedimentos Metodológicos}

Como abordagem de investigação, nossa pesquisa tem como suporte metodológico para a geração de dados a pesquisa-ação, visto que busca investigar uma parcela da complexidade dos fatores que envolvem a pesquisa; como afirma Creswell (2010), trata-se de uma pesquisa com pessoas, em vez de sobre ou para pessoas, fato este que nos leva a nominar esses futuros professores de língua materna como colaboradores da nossa pesquisa, ao invés de meros participantes ou sujeitos. E, entendendo que nosso estudo busca intervir no ensino aprendizagem de práticas multiletradas na didatização dos componentes curriculares de Língua Portuguesa, o presente trabalho adquire, ainda, um caráter intervencionista.

Tendo em vista a convicção integradora empreendida neste trabalho, assumimos o caráter transdisciplinar, transgressivo e crítico do campo da Linguística Aplicada - LA (MOITA LOPES, 2006). Nesse sentido, nossos objetos de estudo são situados - gerados em contexto específico de comunicação; múltiplos - de tipos diversos, gerados por sujeitos que apresentam subjetividades e identidades construídas por realidades distintas que, por isso, podem apresentar motivações e engajamentos que podem variar (GEE, 2001) - e, também, complexos, exigindo, assim, metodologias de geração de dados e de análise de resultados que acompanhem sua complexidade e múltiplos campos de interpretação e geração de conhecimento.

A partir dos referenciais teórico-metodológicos que discutimos na disciplina de Prática de Projetos Pedagógicos, ressignificada como um Programa de Multiletramentos Didáticos (PROMULD), a saber: os projetos de letramentos (KLEIMAN, 1995); os multiletramentos (ROJO, 2012); e os projetos didáticos de gênero (KERSCH; GUIMARÃES; 2012, 2014, 2016), propusemos aos futuros professores a construção de projetos didáticodigitais (PDDs) com alunos da Educação Básica, da rede pública, na cidade de Balsas - MA.

Conforme explicitado em Martins (2020, p. 108), nosso Programa de multiletramentos didáticos caracteriza-se como uma pedagogia de projetos sistematizada a partir de uma rede de atividades acadêmico-profissionais, organizadas sob a mediação colaborativa de alunos e professores, que, por meio da escrita (auto)reflexiva, busca desenvolver o ensino-aprendizagem da língua com os gêneros multimodais num dado contexto social, 
oportunizando a construção de letramentos didático-digitais. Conceituamos Letramentos didático-digitais como as capacidades individuais e sociais de mobilizar ações pedagógicas que transformem artefatos digitais em instrumentos de ensino, visando às práticas situadas de uso responsivo da leitura e da escrita nas diversas instituições sociais.

A tomada de decisão em propor a construção de projetos didático-digitais foi por entendermos que o gênero 'projeto didático' permitiria aos alunos de Letras vivenciar eventos e práticas de letramentos próprios do contexto de trabalho desse futuro professor: a prática social letrada na escola, realizando, assim, atividades próprias dessas instituições com legitimidade. Dessa forma, pretendendo auxiliar os futuros professores na apreensão de informações a respeito do contexto e dos sujeitos, com/para os quais os projetos didáticos digitais seriam arquitetados, propusemos atividades de imersão/intervenção nas esferas reais do contexto das escolas de educação básica ao longo da disciplina: entrevista com gestores, professores de língua portuguesa; observação das aulas, relatórios e rodas de conversa com os demais colegas do curso de Letras e a professora orientadora para discussão das informações geradas. Entendemos que esses procedimentos proporcionaram aos futuros docentes percepções valiosas na hora de identificar, selecionar, planejar e avaliar os processos de ensino e de aprendizagem de língua materna nas escolas, como também, as suas próprias formações em licenciatura na universidade.

Convidamos nossos colaboradores de pesquisa a saírem da esfera epistêmica da academia, como somente graduandos de Letras, e os instigamos a assumir/construírem seu papel como futuros professores de língua, ao vivenciarem as práticas sociais letradas nas escolas da rede pública, integrando (novas) tecnologias digitais, que requerem novas posturas na produção de sentido e significado com gêneros textuais, e, assim, motivá-los a uma postura de práxis educativa ${ }^{1}$ ao oportunizar perspectivas didáticas com os desafios educacionais do terceiro milênio que os esperam.

\footnotetext{
1 Orientada nas ideias de Sánchez Vázquez (1977) e Santomé Torres (1991), compreendo a ação docente como práxis, mais especificamente uma práxis criadora, visando à formação humana do docente. Na perspectiva de que esse deva ser o objetivo central na formação de (futuros) educadores. Para isso, o (futuro) professor necessitará 
É preciso ressaltar que o processo de reflexão e reescrita perpassou toda a produção dos referidos projetos. Assim, passados dois meses de aulas e atividades, foram solicitadas às equipes as primeiras versões do projeto, as quais foram discutidas e (re) avaliadas conjuntamente entre a professora formadora do curso de Letras, a professora da rede básica e os futuros professores, durante uma semana, para concluir-se a versão final. Os futuros professores organizaram-se em seis equipes. Então, solicitamos que os PDDs fossem apresentados em sala de aula às demais equipes e também disponibilizados no grupo fechado da disciplina no Facebook. Em ambos os casos, em arquivos de Power Point.

Quadro 01- Orientações para a Produção do PDD

\$Queridosalun@s,

\section{ORIENTAÇÕES}

A partir das informações e percepções geradas nos contextos das escolas em que vocês vivenciaram as últimas semanas, solicito que produzam um Projeto Didático Digital e o postem no grupo do Facebook, como apresentação em Power Point, contemplando os itens abaixo:

Capa: com nomes dos componentes; nome da disciplina, nome do docente, nome da escola onde o PDD será desenvolvido, título do projeto, quantidade de alunos atendida no projeto, turno, série/ano escolar;

* Objetivos (geral e específicos): atentem que os objetivos são para os alunos e não para os professores;

* Justificativa: o porquê do assunto escolhido pela equipe; o porquê dos gêneros selecionados escolhidos e o porquê do tema (e assunto) do projeto dialoga com a prática social dos alunos sujeitos do projeto;

* Referencial teórico: Concepções de linguagem, de aprendizagem e de gramática adotadas pela equipe para o desenvolvimento do projeto, como também os conceitos de cada gênero abordado com a turma. Durante a construção do referencial teórico, é importante que a equipe fundamente teoricamente a relação entre os gêneros desenvolvidos junto com os alunos nas produções das atividades, bem como as mídias e artefatos digitais utilizados. Por exemplo: o que é crônica, o que é roteiro, o que é curta metragem, o que é meme, o que é Facebook, etc;

* Metodologia: descrever os procedimentos, passo a passo, para o desenvolvimento do projeto; gêneros produzidos, ferramentas e/ou ambientes digitais a serem utilizados no projeto.

* Recursos didáticos: todos os recursos utilizados (digitais ou não);

* Cronograma: quantas horas/aulas foram necessárias para cada etapa do projeto.

Bom trabalho e mãos à obra!

Quaisquer dúvidas, já sabem, só chamar!

Abraços!

Professora Ana Patrícia.

de um conhecimento pedagógico que fundamente sua prática e que o convide à reflexão, principalmente quando esta é realizada por um coletivo colaborativo. 


\section{Análise e Discussão dos Dados}

Explicitado o contexto de produção, apresentamos no Quadro 02 a situação de produção dos Projetos didático-digitais (PDD) dos futuros professores. A fim de sintetizarmos as ideias expostas, são estruturados os principais fatores da situação de produção que podem incidir na forma de organização textual.

Quadro 02 - Representações dos mundos físico e sociosubjetivo dos PDDs

\begin{tabular}{|c|c|c|c|c|}
\hline & $\begin{array}{c}\text { Lugar de } \\
\text { produção }^{2}\end{array}$ & $\begin{array}{c}\text { Momento de } \\
\text { produção }\end{array}$ & Agente-produtor & Leitor \\
\hline $\begin{array}{l}\text { Mundo } \\
\text { Físico }\end{array}$ & $\begin{array}{l}\text { Residência dos } \\
\text { futuros } \\
\text { professores }\end{array}$ & $\begin{array}{l}\text { Após dois meses } \\
\text { de aula e ativida- } \\
\text { des de inserção } \\
\text { nas escolas da rede } \\
\text { básica. }\end{array}$ & $\begin{array}{l}\text { Acadêmicos do } 4^{\circ} \\
\text { período de Letras } \\
\text { noturno, em } \\
2017.2 \text {. }\end{array}$ & $\begin{array}{l}\text { Profa. de PPP, } \\
\text { prof. }^{a} \text { da escola e } \\
\text { acadêmicos do } 4^{\circ} \\
\text { período de Letras } \\
\text { noturno, em 2017.2. }\end{array}$ \\
\hline & $\begin{array}{l}\text { Lugar social } \\
\text { de produção }\end{array}$ & $\begin{array}{c}\text { Objetivo- } \\
\text { propósito } \\
\text { comunicativo }\end{array}$ & $\begin{array}{l}\text { Papel social do } \\
\text { enunciador }\end{array}$ & $\begin{array}{c}\text { Papel social do } \\
\text { destinatário }\end{array}$ \\
\hline $\begin{array}{c}\text { Mundo } \\
\text { Sociossubjetivo }\end{array}$ & $\begin{array}{l}\text { Universidade - } \\
\text { contexto aca- } \\
\text { dêmico }\end{array}$ & $\begin{array}{l}\text { Propor e apresen- } \\
\text { tar em Power } \\
\text { Point atividades } \\
\text { didáticas, a partir } \\
\text { das práticas sociais } \\
\text { letradas e digitais } \\
\text { dos alunos da rede } \\
\text { básica. }\end{array}$ & $\begin{array}{l}\text { Futuro professor } \\
\text { que reflete acerca } \\
\text { das práticas sociais } \\
\text { letradas e digitais, } \\
\text { a partir dos usos } \\
\text { reais do contexto } \\
\text { escolar vivenciado. }\end{array}$ & $\begin{array}{l}\text { Profa. de PPP que } \\
\text { atua na orientação e } \\
\text { coordenação do } \\
\text { PROMULD; Prof } \\
\text { da escola da rede bá- } \\
\text { sica, os alunos das } \\
\text { escolas e os colegas } \\
\text { acadêmicos do } 4^{\circ} \\
\text { período de Letras } \\
\text { noturno, em 2017.2. }\end{array}$ \\
\hline
\end{tabular}

Fonte: Martins (2020).

Argumentamos a identificação dos leitores (mundo físico) e dos papéis sociais dos destinatários (mundo sociosubjetivo) para além da professora do PROMULD, haja vista entendermos que a produção dos projetos didáticos não consistia meramente em uma atividade acadêmica para a professora, mas, sobretudo, tratava-se de uma construção COM e PARA os nossos colaboradores sujeitos envolvidos nas práticas letradas desenvolvidas.

Apresentados os fatores constituintes do contexto de produção dos projetos dos

\footnotetext{
2 Ainda que entendamos que as práticas sociais de leitura e escrita estão cada vez mais móveis e flexíveis na contemporaneidade e que, portanto, o lugar físico e material não necessariamente seja aqui a residência do futuro professor, consideramos a "residência do aluno" como lugar físico, ressignificando-o como lugares outros que não a universidade. No caso em questão, lugar onde produziriam suas atividades acadêmicas quando não estivessem no espaço físico destas, mesmo que estejamos cientes da pluralidade que esse termo possa causar.
} 
futuros professores, daremos continuidade ao nosso estudo por meio da análise do nível organizacional. Iniciaremos pelo plano global do texto e, em seguida, veremos os tipos de discurso e os mecanismos enunciativos.

\section{Análise do nível organizacional e dos mecanismos enunciativos}

Conforme demonstrado no Quadro 01, foi solicitada aos futuros professores uma escrita orientada aos parâmetros normativos à estrutura do gênero acadêmico profissional do projeto de ensino. No que diz respeito ao plano global do texto, foi possível percebermos que os projetos de todas as seis equipes apresentaram os itens solicitados na estrutura organizacional do texto. Contudo, no que se refere à construção dos objetivos e dos procedimentos metodológicos, foram necessárias adequações entre a produção inicial do projeto e sua versão final. Quanto aos objetivos, o fator que precisou de maior orientação foi a compreensão dos futuros professores de que os objetivos pensados no projeto não são para os professores, mas sim devem ser pensados para e com os alunos.

Vale ressaltar que, mesmo antes da produção inicial dos projetos didáticos pelos futuros professores, foram propostas durante o PROMULD a análise e a discussão de projetos pedagógicos selecionados em sites educativos (por ex.: Portal do professor, Nova Escola, Canal Futura, etc). O propósito dos objetivos foi um aspecto bastante discutido, uma vez que vários dos projetos encontrados em tais sites apresentavam objetivos pensados como ponto de chegada o professor e não o aluno.

No que tange aos procedimentos metodológicos, a didatização dos artefatos digitais e com os gêneros textuais para o ensino com os alunos foram os aspectos que mais discussão e reflexão demandaram nos encontros de orientação. Notamos que a dificuldade dos futuros professores não residia mais (como na produção inicial) na identificação dos gêneros presentes nas práticas sociais do contexto escolar vivenciado. A dificuldade estava em como ultrapassar a esfera do cotidiano para adentrar no ambiente escolar, sem, contudo, deixar de construir sentido real nas práticas letradas daqueles alunos, isto é, a maior dificuldade estava em encontrarmos um terceiro espaço.

Pahl e Rowsell (2005, p. 23) asseguram que o letramento está ligado com a nossa 
identidade e com as nossas práticas. Conforme pontuam, a formação de nossas práticas de letramento ocorre em uma série de domínios diferentes, por exemplo, casa, escola e local de trabalho. Assim, assumir uma abordagem que entenda o letramento como uma prática social envolve uma série de pensamentos-chave, envolve reconhecer que a escola é apenas um dos cenários onde o letramento ocorre. Isto reconhece que os recursos usados para ensinar em sala de aula podem ser diferentes, em diálogo com os recursos utilizados pelos alunos em suas casas.

Ao problematizar as relações entre o que se aprende na escola (em nosso caso, na universidade e a formação inicial de professores) e o que se vive fora dela, as autoras elucidam a relevância de pensarmos numa perspectiva didática como um terceiro espaço. Desse modo, ao reconhecermos práticas de letramentos dos nossos alunos, estamos reconhecendo suas identidades. Estas identidades, então, tornam-se mais visíveis na aula, uma vez que podem ser incentivados a trazer, de fora da sala de aula, os marcadores de identidade que atribuem sentido. As autoras asseguram, portanto, que parte desse trabalho reconhece que as identidades podem ser expressas em artefatos e aquele pode, então, cruzar diversas práticas locais. Por isso, as escolas podem oferecer 'espaços terceiros', os quais podem permitir a identidade dos alunos para serem reconhecidos e, assim, trazer os interesses da comunidade, as formas pelas quais a comunidade funciona, o que favorece identificarmos os recursos da comunidade local que os alunos podem trazer para a escola.

Tendo em vista que os encontros da disciplina na universidade aconteciam simultaneamente às práticas pedagógicas dos futuros professores nas escolas, nossas orientações e instruções foram mais facilmente compreendidas por eles, permitindo, inclusive, maior autonomia, responsividade e responsabilidade daqueles no processo de (re) construção de seus projetos didático-digitais. Dessa forma, assumimos as versões finais dos PDDs para nossa análise, entendendo que estas podem refletir, em maior ou menor grau, a influência da esfera acadêmica, da esfera das escolas da rede básica e das práticas cotidianas dos futuros professores e de seus alunos. Nesse sentido, sistematizamos no Quadro 03 os gêneros textuais elencados pelos futuros professores na produção dos PDDs, identificando as esferas de comunicação correspondentes: 
Quadro 03 - Equipes e PDDs da disciplina de PPP

\begin{tabular}{|l|l|l|l|}
\hline \multicolumn{1}{|c|}{ GRUPOS } & \multicolumn{1}{|c|}{ TITULO DO PDD } & \multicolumn{1}{c|}{$\begin{array}{c}\text { GÊNEROS/ } \\
\text { SUPORTES/TECNOLOGIAS }\end{array}$} & \multicolumn{1}{c|}{$\begin{array}{c}\text { PÚBLICO } \\
\text { ALVO }\end{array}$} \\
\hline $\begin{array}{l}\text { Equipe I } \\
\text { (Vânia) }\end{array}$ & Como Vejo Minha Escola? & $\begin{array}{l}\text { Tabelas; Resumo; Painéis Infor- } \\
\text { mativos; Fotografias com smar- } \\
\text { tphones; Oficinas de produção e } \\
\text { edição de fotografias. }\end{array}$ & $\begin{array}{l}7^{\circ} \text { ano/ } \\
\text { Vespertino }\end{array}$ \\
\hline $\begin{array}{l}\text { Equipe II } \\
\text { (Mauro) }\end{array}$ & $\begin{array}{l}\text { Produzindo Artigo de Opinião } \\
\text { de maneira colaborativa: } \\
\text { o uso do Google Drive. }\end{array}$ & $\begin{array}{l}\text { Artigo de Opinião; Google Drive; } \\
\text { Whatsapp; celulares e } \\
\text { Facebook. }\end{array}$ & $\begin{array}{l}8^{\circ} \text { ano/ } \\
\text { Vespertino }\end{array}$ \\
\hline $\begin{array}{l}\text { Equipe III } \\
\text { (Maria) }\end{array}$ & $\begin{array}{l}\text { O uso do Gênero Meme no en- } \\
\text { sino das Figuras de Linguagem }\end{array}$ & $\begin{array}{l}\text { Atividades do livro didático; } \\
\text { Meme; Facebook; WhatsApp. }\end{array}$ & $\begin{array}{l}8^{\circ} \text { ano/ } \\
\text { Vespertino }\end{array}$ \\
\hline $\begin{array}{l}\text { Equipe IV } \\
\text { (Beatriz) }\end{array}$ & $\begin{array}{l}\text { Redação do ENEM: impacto, } \\
\text { visão e dificuldades }\end{array}$ & $\begin{array}{l}\text { Redação do ENEM; } \\
\text { Facebook. }\end{array}$ & $\begin{array}{l}3^{\circ} \text { ano do EM/ } \\
\text { Matutino }\end{array}$ \\
\hline $\begin{array}{l}\text { Equipe V } \\
\text { (Júlia) }\end{array}$ & Conto, Câmera, Ação. & $\begin{array}{l}\text { Conto; Roteiro; Vídeo do Face- } \\
\text { book; } \\
\text { Oficinas sobre Produção e Edição } \\
\text { de Vídeos; Curta-metragem. }\end{array}$ & $\begin{array}{l}1^{\circ} \text { ano do } \\
\text { EJA/noturno }\end{array}$ \\
\hline $\begin{array}{l}\text { Equipe VI } \\
\text { (Carla) }\end{array}$ & $\begin{array}{l}\text { A inserção da tecnologia na } \\
\text { produção dissertativa. }\end{array}$ & $\begin{array}{l}\text { Roda de conversa; Sites da inter- } \\
\text { net; WhatsApp; Textos de divulga- } \\
\text { ção científica. }\end{array}$ & $\begin{array}{l}3^{\circ} \text { ano do EM/ } \\
\text { Matutino }\end{array}$ \\
\hline
\end{tabular}

Fonte: Elaborado pelas autoras.

O Quadro acima apresenta os gêneros e artefatos identificados nos PDDs das seis equipes. É possível observarmos a predominância dos artefatos digitais mais comuns nas práticas sociais dos alunos e dos futuros professores entre os gêneros, suportes textuais e artefatos digitais elencados para as atividades didáticas (Facebook, Whatsapp, vídeos, fotografias, memes). Conforme já mencionado, as versões apresentadas passaram por revisões e discussões até serem finalizadas.

Kleiman (2007) ressalta o papel da escola como principal agência de letramento da sociedade e, por isso, ela pode oportunizar o diálogo com os múltiplos letramentos da vida social, como o objetivo estruturante do trabalho escolar em todos os ciclos, criando espaços para experenciar formas de participação nas práticas sociais letradas, tendo a prática social como ponto de partida e de chegada da aprendizagem. Segundo a autora, 
[...] os estudos do letramento nos mostram, e isto é muito importante para a reflexão curricular, que os eventos de letramento exigem a mobilização de diversos recursos e conhecimentos por parte dos participantes das atividades. Isso significa que alguns eventos de letramento voltados para a resolução de alguma meta da vida social criarão, sem dúvida alguma, inumeras oportunidades de aprendizagem para os participantes, todas elas diferentes entre si, segundo as diferenças existentes entre os individuos participantes. Cabe ao professor destacar e sistematizar aqueles aspectos que fazem parte de seu planejamento semestral, anual ou cíclico, tantas vezes quanto forem necessárias, para o aluno adquirir confiança e autonomia com relação ao conteúdo visado. (KLEIMAN, 2007, p. 15 , grifo nosso)

Kleiman (2007) propõe uma perspectiva de ensino aprendizagem que parta das reais práticas sociais letradas, com problemáticas reais, que possibilitem a agentividade do aluno e torne significativo o aprendizado depreendido nos eventos de letramento. Observamos a modalização da autora no final do parágrafo ao enfatizar a importância da reflexão e do domínio curricular por parte do professor para a adequada seleção e sistematização dos conteúdos e atividades a serem desenvolvidos.

Vale destacar que em todos os PDDs percebemos a preocupação dos futuros professores em dialogar com as reais necessidades dos contextos escolares trabalhados, impulsionando, ainda, o protagonismo de seus alunos em relação aos multiletramentos. Acerca disso, mencionamos novamente Kleiman, quando esta ratifica a importância do trabalho didático com a cultura das linguagens impressa e digital, através de diversos exemplos de situações de ensino e de aprendizagem. Kleiman (2014) discute mais especificamente sobre práticas de letramento digital e textos multimodais, os multiletramentos das culturas impressa e digital, mantendo como pano de fundo da discussão os objetivos e funções do letramento escolar e a formação do professor que quer efetivamente atuar como agente de letramento do mundo contemporâneo.

Nesse sentido, o grupo de Nova Londres está acertado em considerar os multiletramentos objeto pedagógico relevante para o aluno da escola contemporânea. No entanto, a dimensão da contemporaneidade no ensino de práticas de letramento não tem somente a ver com o ensino daquilo que há de mais avançado tecnologicamente, ou aquilo que é mais funcional e, portanto, terá maior serventia escola afora, embora ambos sejam aspectos importantes 
para determinar objetivos educacionais. A contemporaneidade diz respeito à flexibilidade e ao respeito pela cultura do outro para garantir a inserção tranquila do aluno nos novos modos de fazer sentido via escrita na sociedade tecnológica em que imagem e texto escrito imperam. Ser contemporâneo é ouvir o que o outro quer e aproveitar a flexibilidade de novos modos de ser e significar para propiciar as condições para que o aluno satisfaça seu desejo. (KLEIMAN, 2014, p. 11-12, grifos nossos)

Na citação, identificamos a menção direta da autora ao Grupo de Nova Londres e à pedagogia dos multiletramentos como perspectiva de ensino. Contudo, contrapõe-se à relação unívoca, por vezes colocada como sinonímia, entre multiletramentos, contemporaneidade e tecnologia; sublinhando, então, a relevância no ensino de práticas de letramentos que assumam uma postura flexível e de respeito cultural às novas formas de produzir sentido nas multimodalidades e multissemioses textuais. A premissa apontada pela autora nos permite pontuar também o desenvolvimento do letramento didático-digital dos futuros professores, haja vista que nas versões iniciais dos PDDs era perceptível a dificuldade daqueles em dialogar numa perspectiva de terceiro espaço, em que o impresso, o digital, o escolar e o extraclasse pudessem oportunizar uma aprendizagem significativa às suas práticas sociais.

Nos seis projetos, percebemos a predominância de segmentos de tratamento temático do tipo de discurso relato interativo nos tópicos Metodologia e Justificativa. Os segmentos identificados apresentam organizadores temporais explícitos, além da predominância de verbos no futuro, a presença de organizadores temporais indicadores da origem espaço-temporal, de forma explícita, e a presença de pronomes de $1^{\mathrm{a}}$ e $2^{\mathrm{a}}$ pessoa do singular e do plural referentes aos protagonistas da interação existente no relato. Observemos no Quadro 04, segmentos que comprovam nossa constatação. 
Quadro 04-Segmentos de tratamento temático do tipo de discurso relato interativo nos PDDs

\begin{tabular}{|c|c|}
\hline EQUIPES & SEGMENTOS DE TRATAMENTO TEMÁTICO \\
\hline $\begin{array}{c}\text { Equipe I } \\
\text { (Vânia) }\end{array}$ & 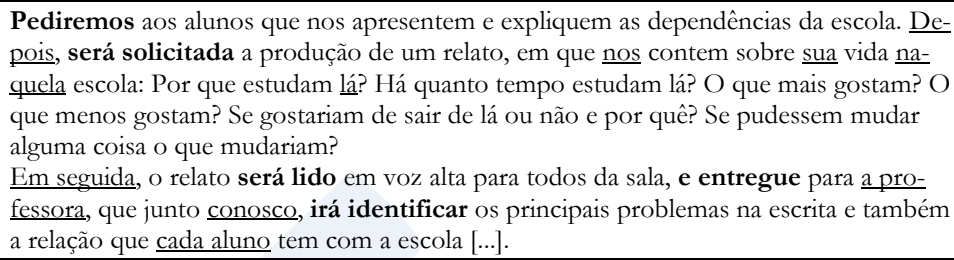 \\
\hline $\begin{array}{c}\text { Equipe V } \\
\text { (Júlia) }\end{array}$ & $\begin{array}{l}\text { Para a realização do projeto, será explanada uma aula sobre o gênero Conto com os } \\
\text { alunos, a fim recapitular esse conteúdo que será trabalhado no decorrer do projeto. } \\
\text { Logo após, será realizada a divisão dos grupos para trabalhar o conto A Cartomante, } \\
\text { de Machado de Assis. Depois, desenvolveremos uma oficina para auxiliar os alunos } \\
\text { na produção de seus vídeos, orientando-os desde a produção do roteiro à gravação do } \\
\text { vídeo, utilizando um roteiro auxiliador. Simultaneamente, será criado um grupo fe- } \\
\text { chado no Facebook para postagens dos curtas metragem [...]. }\end{array}$ \\
\hline
\end{tabular}

Fonte: Elaborado pela primeira autora

De acordo com Bronckart (2011), o tipo de discurso relato interativo pode trazer à tona as reflexões sobre o trabalho empírico com os gêneros textuais. Desse modo, entendemos que nos discursos dos futuros professores são reveladas suas experiências pessoais no trabalho com gêneros de texto. Considerando que as versões finais dos PDDs são produtos de suas experiências e (con)vivência nos contextos escolares, interpretamos que a exposição da sequencialidade temporal das atividades previstas se refere às questões praxiológicas do trabalho com os gêneros e artefatos digitais selecionados pelos futuros professores.

Argumentamos que a organização do raciocínio usando o relato interativo, que aparece em quantidade maior nos PDDs, indicia uma lógica de disjunção implicada no mundo discursivo do narrar, demonstrando capacidades linguístico-discursivas que se relacionam mais especificamente com a transposição didática dos gêneros e artefatos digitais e sinalizam, deste modo, índices de continuum no desenvolvimento do letramento didático digital dos futuros professores, ao exigir que estes adequem-se discursivamente ao contexto de interlocução na produção e apresentação em Power Point dos PDDs.

Nesse sentido, em termos de construção e desenvolvimento do letramento didáticodigital, observamos que a escrita reflexiva sobre e para o local de trabalho em sua perspectiva 
praxiológica é ressignificá-la e torná-la instrumento para o agir dos (futuros) professores. Para aprofundarmos essa reflexão, analisemos, então, as vozes enunciativas e as modalizações que denotam a responsabilidade do agir dos futuros professores na construção dos Projetos didático-digitais.

A princípio, identificamos os personagens presentes nos PDDs; em seguida, apresentamos segmentos de discurso em que aparecem as vozes de autor empírico ${ }^{3}$.

Quadro 05 - Personagens recorrentes nos PDDs

\begin{tabular}{|l|c|c|c|c|c|c|}
\hline \multirow{2}{*}{\multicolumn{1}{|c|}{ PERSONAGENS }} & \multicolumn{6}{c|}{ TOTAL DE OCORRÊNCIAS } \\
\cline { 2 - 7 } & Equipe I & $\begin{array}{c}\text { Equipe } \\
\text { II }\end{array}$ & $\begin{array}{c}\text { Equipe } \\
\text { III }\end{array}$ & $\begin{array}{c}\text { Equipe } \\
\text { IV }\end{array}$ & $\begin{array}{c}\text { Equipe } \\
\text { V }\end{array}$ & $\begin{array}{c}\text { Equipe } \\
\text { VI }\end{array}$ \\
\hline Professora da Universidade & 03 & 00 & 01 & 00 & 00 & 00 \\
\hline Professora da educação básica & 06 & 01 & 01 & 01 & 00 & 00 \\
\hline Alunos das escolas & 16 & 12 & 07 & 03 & 12 & 04 \\
\hline
\end{tabular}

Fonte: Elaborado pelas autoras com base nos PDDs.

Conforme percebemos no Quadro 05, a personagem que predominou nos PDDs foi os alunos das escolas, demonstrando, assim, a relevância dada a estes pelos futuros professores como agentes no planejamento das ações didáticas. Por outro lado, verificamos um quase apagamento da professora da universidade e da escola. Sendo a primeira colocada como agente da ação apenas em dois projetos e a segunda em quatro dos seis. Interpretamos essa pouca recorrência às referidas professoras como uma autonomia dos futuros professores, construída e ratificada ao longo das reescritas dos PDDs.

“[...] Após a exposição de imprevistos e dificuldades para desenvolvimento do projeto, como a mudança abrupta no calendário letivo nas escolas municipais, nos reunimos com a professora Ana Patrícia. A professora nos ajudou a repensar nos gêneros e nos orientou a reler nossos dados acerca da escola, catalogados no período de observação e entrevistas com o gestor e a professora. Foi quando decidimos pelas fotografias com os celulares dos alunos e cartazes de valorização da escola [...]". (PDD I)

\footnotetext{
${ }^{3}$ Tendo em vista que os PDDs foram produzidos de maneira colaborativa e coletivamente, consideraremos como voz de autor empírico a $1^{\text {a }}$ pessoa do plural (nós), a qual foi percebida em duas formas, sinalizando o agir coletivo, como explicaremos mais adiante.
}

${ }^{4}$ Mencionada nos PDDs pelo nome da professora. 
"A professora Ana Patrícia nos ajudou na escolha pelo gênero meme, quando mencionamos que os alunos costumavam fazê-lo durante as aulas, sendo parte da prática social deles. Com isso, conseguiríamos trabalhar com as figuras de linguagem na compreensão do sentido denotativo e conotativo em textos". (PDD III)

É possível perceber que nas únicas vezes em que a professora da universidade foi identificada foi enquanto agente colaboradora no processo de escolha dos gêneros e artefatos para o desenvolvimento do projeto. As marcas verbais ajudou e orientou de valor psicológico e, ao nosso ver, também apreciativo, sugerem a interlocução que ocorreu entre os futuros professores e sua orientadora na universidade. Notamos a negociação em torno da prática com os gêneros textuais e os artefatos digitais, bem como os dilemas envolvidos em relação às escolhas no âmbito do trabalho do professor de língua materna.

Segundo Reichmann (2015), o desafio em relação à escolha do gênero a ser trabalhado em sala de aula envolve uma posição responsiva ativa. Nos discursos aqui analisados, verificamos que foi o dizer da professora da universidade que prefigurou o trabalho dos futuros professores, haja vista que, após as orientações da professora, o trabalho de planejamento das ações didáticas passa a tomar forma. Assim como a autora, entendemos que, apesar da aparente invisibilidade, há também uma adesão à voz da professora universitária, que oportunizou vários eventos de letramento acadêmico-profissionais durante (no nosso caso) o PROMULD.

Nos trechos dos PDDs das equipes II e IV, identificamos o objetivo dos futuros professores em transformar os artefatos e mídias digitais - celulares e Facebook, respectivamente, em instrumentos de ensino:

“Elegemos o tema 'Os pós e contra no uso dos celulares na escola' para o projeto, por vermos muitos alunos usando celulares no Whatsaap durante as aulas, mesmo a professora pedindo que guardassem [...]”. (PDD II)

"Tal escolha foi porque a professora apontou essa plataforma como um dos principais empeci$\underline{\text { lhos }}$ enfrentados durante as aulas. Por isso, pretendemos transformá-lo em um auxiliador [...]”. (PDD IV)

Desse modo, entendemos que as professora universitária e professora da escola são mencionadas como agentes que influenciam na tomada de responsabilidade do agir na construção dos projetos didático-digitais. Por isso, ressaltamos a relevância do professor 
formador e do professor colaborador da escola na articulação, construção e desenvolvimento do letramento didático-digital na formação inicial de professores.

Quanto aos personagens alunos, identificamos que estes são configurados como agentes das ações pedagógicas planejadas nos projetos. Como demonstrado no Quadro 05, a recorrência à personagem alunos das escolas foi predominante. Em todos os projetos, eles foram maioria em relação às professoras, com um número expressivo de ocorrências, com exceção dos projetos das equipes IV e VI, os quais apresentaram uma extensão do texto menor e concentraram-se, consideravelmente, nas vozes de autor empírico.

"Os alunos pesquisarão em sites informações sobre o uso do celular pelos adolescentes (dentro e fora da escola). Depois, criarão uma conta no Google e conhecerão os principais recursos do Google Docs em computadores e também nos celulares. Em seguida, construirão argumentos prós e contra o uso de celular na escola, e produzirão um artigo de opinião sobre o uso de celular na escola, de maneira colaborativa utilizando o Google Docs. Ao final, apresentarão os artigos de opinião produzidos, fazendo comentários para os colegas e professores". (PDD II)

"Os alunos responderão as atividades do livro didático, acompanhados pelo nosso grupo. [...] Postarão os memes no grupo criado no whatssap e explicarão a conotação e as figuras de linguagens presentes, mostrando a função delas para a construção de sentido dos memes". (PDD I)

"Com o acesso ao Facebook ,os alunos trocarão informações e conhecimentos para a análise do Conto e produção dos vídeos, internalizando o conteúdo proposto através de suas práticas sociais rotineiras, e potencializando o conhecimento digital que eles já possuem". (PDD III)

Os excertos acima foram retirados de segmentos dos discursos presentes na metodologia nos PDDs. É notoriamente perceptível como os futuros professores demandam os alunos como agentes nos procedimentos didáticos planejados, com a presença de vários verbos de ação, além da preocupação com a escrita situada e contextualizada às práticas sociais dos alunos.

Considerando que os maiores quantitativos de vozes enunciativas identificadas nos PDDs foram a voz personagem dos alunos das escolas e a voz de autor empírico do coletivo dos futuros professores, argumentamos a forte relação dialógica existente entre essas vozes. Ou seja, há a implicação da presença do outro como princípio constitutivo da produção e recepção do discurso. Nesta perspectiva, a alteridade do sujeito se constitui na relação criadora do encontro, concretizada em “"...] sobreposições do sentido sobre o sentido, 
da voz sobre a voz, numa intensificação pela fusão e combinação de muitas vožes (um corredor de vozes)" (BAKHTIN, 2011, p. 327, grifo nosso).

Assim, com base nos estudos de Bakhtin e Bronckart, aos quais nos alinhamos, entendemos que os futuros professores tomaram o evento discursivo como um acontecimento verbal concreto, vivo e materializado numa relação imediata com a realidade. Essa relação se presentifica em um processo de compreensão que envolve a responsividade e, por conseguinte, juízo de valor (BAKHTIN, 2011, p. 328, grifos do autor). Nesse sentido, a voz dos alunos revela, notadamente, a implicação destes e a divisão da responsabilidade, talvez não apenas da responsabilidade enunciativa, que é também compartilhada, mas, principalmente, da responsabilidade pelo projeto e pelo trabalho a ser desenvolvido.

No Quadro 06, por sua vez, sistematizamos as ocorrências das vozes de autor empírico identificadas nos PDDs. Considerando a produção dos projetos em equipe, a pessoa verbal nós é aqui interpretada como a voz de autor empírico. Assim, foram percebidas duas formas de apresentação do pronome nós nos projetos: a voz do coletivo dos componentes da equipe e a voz do coletivo futuros professores + seus alunos da escola. Vejamos:

Quadro 06 - Vozes de autor empírico recorrentes nos PDDs

\begin{tabular}{|c|c|c|c|c|c|c|}
\hline \multirow{2}{*}{ PERSONAGENS } & \multicolumn{7}{|c|}{ TOTAL DE OCORRÊNCIAS } \\
\cline { 2 - 7 } & Equipe I & $\begin{array}{c}\text { Equipe } \\
\text { II }\end{array}$ & $\begin{array}{c}\text { Equipe } \\
\text { III }\end{array}$ & $\begin{array}{c}\text { Equipe } \\
\text { IV }\end{array}$ & $\begin{array}{c}\text { Equipe } \\
\text { V }\end{array}$ & $\begin{array}{c}\text { Equipe } \\
\text { VI }\end{array}$ \\
\hline $\begin{array}{c}\text { Nós } \\
\text { (Futuros professores) }\end{array}$ & 12 & 17 & 13 & 06 & 07 & 21 \\
\hline $\begin{array}{c}\text { Nós } \\
\text { (voz coletiva: os Futuros } \\
\text { professores + os seus } \\
\text { alunos) }\end{array}$ & 04 & 02 & 02 & 02 & 02 & 04 \\
\hline
\end{tabular}

Fonte: Elaborado pelas autoras com base nos PDDs.

Notamos que ambas as formas de apresentação do coletivo nós foram recorrentes e todos os projetos, sendo a do coletivo da equipe de trabalho a predominante. Além disso, destacamos a presença, ainda que em minoria, do coletivo futuros professores e seus alunos, haja vista que, em tais ocorrências, é enfatizada a coparticipação dos alunos nas atividades previstas. 
"Após analisarmos o contexto macro da escola, (as entrevistas com gestor e professora, e a observação das aulas), percebemos a necessidade de trabalharmos com produção textual de maneira mais dinâmica, atraente e interativa. Assim, nasceu a ideia de produzirmos o gênero artigo de opinião utilizando o Google drive, que permite a produção de textual de maneira colaborativa. Percebemos que essa proposta vai ao encontro das necessidades reclamadas pela professora na entrevista, pois será o próximo gênero a ser abordado no programa de aulas. Para isso, trabalharemos com a produção de texto com tecnologia no laboratório de informática, o que acreditamos que motivará os alunos, já que durante as observações das aulas, notamos que ficavam presos ao livro, e muitos nem prestavam atenção ao que a professora dizia, ficando durante muito tempo nos celulares". (PDD II)

No trecho acima, a voz de autor empírico do coletivo de futuros professores é indiciada pelo uso de modalizadores apreciativos, como em analisarmos; percebemos; necessidade; maneira mais dinâmica, atraente e interativa; acreditamos; ficavam presos ao livro; notamos. Observamos também a perspectiva praxiológica na organização das ações didáticas, revelando a postura do futuro professor sobre o seu agir profissional, ao utilizar modalizadores como produzirmos; trabalharemos; de maneira colaborativa.

\begin{abstract}
"Almejávamos com este projeto desenvolver uma proposta de atividade para o ensino aprendizagem da língua portuguesa [...] para o $3^{\circ}$ ano. O tema que elegemos é " $\mathrm{A}$ inserção da tecnologia na produção dissertativa". Consideramos um tema interessante de ser trabalhado, pois durante todas as aulas assistidas apenas uma vez, observamos o uso de tecnologia digital, e como se sabe é muito relevante para o ensino e educação o uso da tecnologia. Portanto, visamos esclarecer que a sociedade em que vivemos é mediada pela tecnologia, e, em razão disso, não dá para imaginar uma educação sem a utilização de meios tecnológicos. Acreditamos que o processo de ensino-aprendizagem certamente nos mostra que ele já não mais funciona como nos tempos antepassados, pois as formas de ensinar e aprender mudaram radicalmente, isto é, o professor não é mais um simples transmissor do conhecimento. Por isso, organizamos o projeto em etapas, com debates, rodas de conversas, envolvendo as redes sociais para troca de informações, além do exercício de leitura para sustentar suas elaborações”. (PDD VI)
\end{abstract}

No segundo trecho, também percebemos a dimensão apreciativa dos futuros professores no planejamento de suas ações didáticas. Termos e expressões de modalização como consideramos; interessante; apenas uma veż; é muito relevante para o ensino e educação; não dá para imaginar; acreditamos; certamente e radicalmente, são exemplos da implicação dos futuros professores no discurso sobre seu agir. Ressaltamos ainda o emprego de verbos como almejamos; elegemos; observamos; visamos e organizamos, denotando o comprometimento com o que é dito, tomando para si a autoria (e a autoridade) sobre o que é proposto nos projetos. 
No que tange à forma da voz coletiva nós, significando a equipe dos futuros professores e seus alunos, percebemos que as ocorrências a esse tipo de voz de autor referiamse, sobretudo, aos momentos de avaliação das produções previstas.

"[...] Com os alunos, estipularemos o prazo das postagens dos vídeos do projeto Conto, Câmera, Ação. Posteriormente, junto com os alunos, faremos a avaliação dos curtas”. (PDD II)

"[...] Debateremos com os alunos sobre a importância das tecnologias na educação e o uso de celulares nos horários de aula. Em seguida, juntamente com a turma, avaliaremos os textos dissertativos, destacando, os erros, e depois solicitaremos a reescrita, conforme as instruções feitas coletivamente". (PDD VI)

Embora com ocorrência relativamente baixa, essa voz traz para o texto a presença de uma estratégia linguístico-textual que enfatiza a responsabilização enunciativa do que é dito. Torna-se evidente que os futuros professores buscam orientar seu agir (futuro) no trabalho com os gêneros e artefatos digitais, de modo a responder às orientações e práticas experenciadas durante o PROMULD. As análises das vozes enunciativas dos PDDs nos revelam um gesto de autocontrole na consciência dos futuros professores no trabalho $\mathrm{COM}$ os gêneros de texto e artefatos digitais, transformando-os em instrumentos, segundo as reais práticas sociais letradas dos contextos de letramento situado.

Diversos elementos presentes na escrita sobre e para o agir dos futuros professores nos PDDs nos permitiram vislumbrar que esses não apenas internalizaram as leituras e orientações acadêmicas, como também reconfiguraram seu agir linguageiro e didático. Essa reconfiguração e reposicionamento, ainda que em construção e num continnum, foram marcados por diferentes índices linguísticos, textuais e discursivos que nos permitem observar o desenvolvimento de suas escritas reflexivas e, consequentemente, traços de seus letramentos didático-digitais (MARTINS, 2020).

\section{Considerações Finais}

Nossa proposta teve como objetivo principal investigar como futuros professores de Língua Portuguesa representam, discursivamente, a (re) construção de suas identidades perante o papel das tecnologias digitais nas suas ações profissionais futuras. Para consecu- 
ção do referido objetivo, empreendemos a ressignificação de uma disciplina curricular obrigatória, que trata da implantação e produção de projetos pedagógicos, e propusemos um Programa de Multiletramentos Didáticos (PROMULD), interpretado como prática letrada e de trabalho colaborativo, voltado para a aprendizagem situada, objetivando uma possibilidade de construção e desenvolvimento de projetos didático-digitais, em termos de construção e desenvolvimento do letramento didático-digital.

Observamos que utilizar a escrita reflexiva para o local de trabalho em sua perspectiva praxiológica é ressignificá-la e torná-la instrumento para o agir dos (futuros) professores. Percebemos que, ao se constituírem sujeitos de sua formação e atuação profissional, os futuros professores revelaram em seus discursos o valor significativo que as ações pedagógicas planejadas suscitavam em suas identidades, simbioticamente implicadas quanto aos aspectos profissional e humano. Ao deixar emergir suas apreciações no para que, como, por que e para quem construíam aquelas ações, os futuros professores denotaram a transformação ocorrida no modo em que pensavam ser a educação e, sobretudo, fazer a educação. Eles puderam sentir e vivenciar que se ensina com os alunos e não para os alunos; se ensina com as nossas práticas sociais e não somente sobre as práticas sociais.

\title{
IDENTITIES IN (DIS)COURSE:
}

\section{PRACTICES OF DIDACTIC MULTILETERATIONS WITH FUTURE TEACHERS}

\begin{abstract}
This study arose from the need to reflect on the professional practices and identities that are (re) (un) revealed in and through the various ways of teaching Portuguese in the current conjuncture of digital technologies. Therefore, a discursive approach was proposed regarding digital technologies and their impact on the construction of teaching identities in initial training. In this sense, we aim to discuss a pedagogical experience of action research developed with students of the languages and literature degree offered at night at a state public university in the city of Balsas - MA. In this way, the article aims to investigate how future Portuguese language teachers represent, discursively, the (re) construction of their identities resulting from the role of digital technologies in their future professional actions. Based on the theoretical assumptions of cultural studies on Identity, Sociodiscursive Interactionism and (Multi) literacies, the analysis of enunciative voices in didactic-digital projects developed by future teachers revealed their awareness of working with text genres and digital artifacts, transforming them into teaching instruments, according to the real literate social practices of the situated literacy contexts. In addition, the discourses for teaching action demonstrated repositioning of teacher identities, although under construction and on a continnum, with traces of their didactic-digital literacies.
\end{abstract}


KEYWORDS: Teaching identities; Initial formation; Digital technologies; Language and Literature Course.

\section{REFERÊNCIAS}

BARTON, David; LEE, Carmen. (orgs.). Linguagem on line: textos e práticas digitais. 1. Ed. São Paulo: Parábola Editorial, 2015.

BRONCKART, J. P. Atividade de linguagem, textos e discursos: por um interacionismo sóciodiscursivo. São Paulo: EDUC, 1999.

BRONCKART, J. P. O agir nos discursos. Campinas: Mercado de Letras, 2008.

BUENO, L. A construção de representações sobre o trabalho docente: o papel do estágio. Tese de Doutorado, LAEL/ PUC SP, 2007.

BUENO, L.; LOPES, M. A. T.; CIRISTÓVÃO, V. L. (Org.) Gêneros textuais e formação inicial: uma homenagem à Malu Matêncio. Campinas: Mercado de Letras, 2013.

CARNIN, Anderson. Na escrita do professor, um percurso possivel para a análise do (seu) desenvolvimento profissional. Tese (doutorado) - Universidade do Vale do Rio dos Sinos, Programa de Pós-Graduação em Linguística Aplicada, São Leopoldo, RS, 2015.

CRESWELL, J. W. Projeto de pesquisa: métodos qualitativo, quantitativo e misto. $3^{\mathrm{a}}$ Ed, Porto Alegre: Artmed, 2010.

GEE, James Paul. Identity as an Analytic Lens for Research in Education. Review of Research in Education, Vol. 25 (2000 - 2001), pp. 99-125. In: American Educational Research Association. Disponível em: http://www.jstor.org/stable/1167322. Acessado em 20/03/2018.

GUIMARÃES, A. M.; CARNIN, A.; KERSCH, D. (Org.). Caminhos da construção: reflexões sobre projetos didáticos de gênero. Campinas, Mercado de Letras, 2015.

GUIMARÃES, A. M.; KERSCH, D. (Org.). Caminhos da construção: projetos didáticos de gênero na sala de aula de língua portuguesa. Campinas, Mercado de Letras, 2012.

HALL, Stuart. A identidade cultural na pós-modernidade. Trad. Tomaz Tadeu da Silva e Guacira Loes Louro. 11. ed. Rio de Janeiro: DP\& A, 2006.

HALL, Stuart. Quem precisa da identidade? Trad.Tomaz Tadeu da Silva. In: SILVA, Tomaz Tadeu da (org.). Identidade e diferença: a perspectiva dos Estudos Culturais. Rio de Janeiro: Vozes, 2000. p. 103-133.

KLEIMAN, A. B. (Org.). Os significados do letramento: uma nova perspectiva sobre a prática social da escrita. Campinas: Mercado de Letras, 1995.

MACHADO, Anna Rachel (org.). O ensino como trabalho: uma abordagem discursiva. Londrina: EDUEL; São Paulo: FAPESP, 2004. 
MATÊNCIO, Maria de Lourdes Meirelles. Estudo da lingua falada e aula de língua materna: uma abordagem processual da interação professor-alunos. Mercado de Letras, 2010.

MARTÍN-BARBERO, Jésus. Dos meios às mediações: comunicação, cultura e hegemonia. Tradução: Ronald Polito e Sérgio Alcides. 5. ed. Rio de Janeiro: Editora UFRJ, 2008.

MARTINS, Ana Patrícia Sá. Processos de (trans) formação de futuros professores e a construção de letramentos didático-digitais. Tese (doutorado) - Universidade do Vale do Rio dos Sinos, Programa de Pós-Graduação em Linguística Aplicada, São Leopoldo, RS, 2020.

MOITA LOPES, L. P. (Org.) Por uma linguistica indisciplinar. São Paulo: Parábola Editorial, 2006.

NÓVOA, António (org.). Profissão professor. Portugal: Porto Editora, 1995. . (org.) Vidas de professores. Portugal: Porto Editora, 1992.

OLIVEIRA, M. do S.; KLEIMAN, A. Letramentos múltiplos. Natal, RN: UDUFRN, 2008.

PAHL, K.; ROWSELL, J. Literacy and Education: Understanding the New Literacy Studies in the Classroom. SAGE Publications, 2005.

PIMENTA, Selma Garrido. (org.) Saberes pedagógicos e atividade docente. São Paulo: Cortez, 2012.

ROJO, R.; MOURA, E. (Orgs.) Multiletramentos na escola. São Paulo: Parábola, 2012.

SILVA, T. T. Documentos de identidade: uma introdução às teorias do currículo. $3^{\mathrm{a}}$ ed. Belo Horizonte: Autêntica, 2011.

Recebido em: 13/04/2020.

Aprovado em: 22/05/2020. 